زمن الاستجابة الحركية للمثيرات (السمعية والبصرية) وعلاقتها بدقة مهارة حائط الصد

بالكرة الطائرة

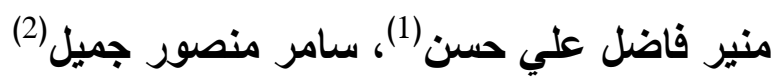

تأريخ تقديم البحث: (2020/9/17)، تأريخ قبول النشر (2020/10/25).

DOI: https://doi.org/10.37359/JOPE.V32(4)2020.1042

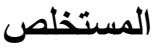

هدفت الدراسة الى التعرف على زمن الاستجابة الحركية للمثيرات السمعية والبصرية وأيضا التعرف على دقة حائط الصد وايجاد

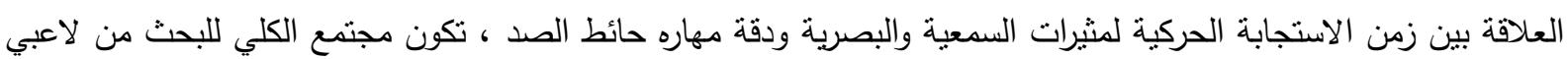

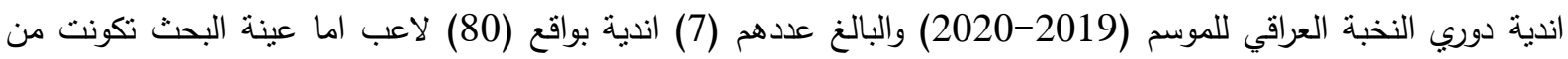
لاعبي نادي الجيش والثرطة الرياضي البالغ عددهم (24) لاعباً، إذ تم استبعاد اللاعب الليبرو وكانت العينة البحث (10)

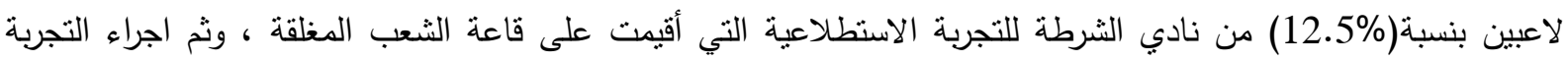

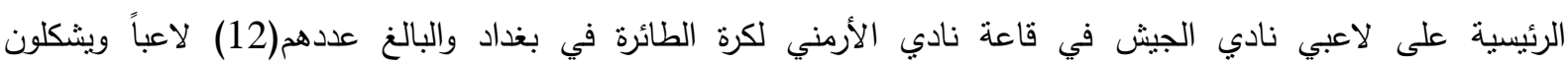
نسبة(15\%) من المجتمع الكلي للبحث وقد استخدم الباحثان المنهج الوصفي بالأسلوب العلاقات الارتباطية ، نم حيث نم

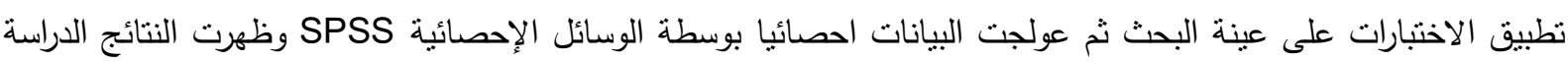
الى وجود علاقات ارتباط معنوية تحت مستوى دلالة (0.05) بين زمن الاستجابة للمثرات(السمعية والبصرية) بدقة مهاره حائط

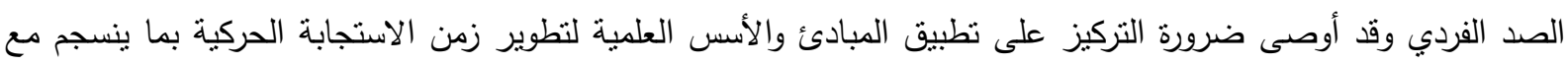

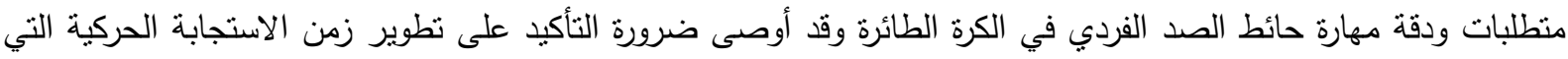
لها تأثثر مباشر على الأداء المهارات الدفاعية للاعبي الكرة الطائرة .

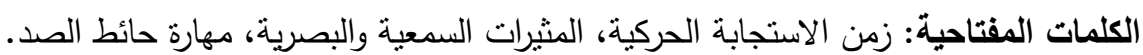

\section{ABSTRACT \\ Time of Motor Response To Stimuli (Auditory and Visual) and Its relationship with Blocking Accuracy In Volleyball}

The research aim at identifying the time of motor response to auditory and visual stimuli as well as identifying the accuracy of blocking and finding the relationship between motor repose time and blocking accuracy. The community were (7) primer soccer league of 2019 2020 and the subjects were (24) volleyball players from Al Jaish and Al Shorta clubs ten players from Al Shorta club performed the pilot study. The researchers used the descriptive method and the data was collected and treated using SPSS. The results showed significant relationship between response time and blocking accuracy. The researchers recommended concentrating on applying scientific principles for developing time of motor response in a manner suitable for blocking in volleyball as well as the necessity of developing time of motor response that directly affect defensive skills of volleyball players.

Keywords: time of motor response, auditory and visual stimuli, and blocking.

(1) طالب دراسات عليا (الماجستبر)، جامعة بغداد، كلية التربية البننية وعلوم الرياضة. (Muneerfadhel92@gmail.com) Mumeer Fadel Ali, Post Graduate Student (Master), University of Baghdad, College of Physical Education and Sport Sciences, (Muneerfadhel92@gmail.com) (009647713311682).

(2) (متاذ مساعد، دكتوراه تربية رياضية، جامعة بغداد، كلية التربية البدنية وعلوم الرياضة (Damer mmmm@yahoo.com) Samer Mansoor Jameel, Assistant Prof (PH.D), University of Baghdad, College of Physical Education and Sport Sciences, (Samer mmmm@yahoo.com) (+964 7804629064). 
ان الكرة الطائرة هي من الألعاب ذات المحيط المفتوح التي تكون مثيراتها سريعة ومتغيرة ومفاجئة (غير معروفة مسبقا) مما يتطلب من اللاعب الاستجابة السريعة والدقيقة لهذه المثيرات لكي يحقق الواجب الحركي بأقل زمن ممكن وكلما

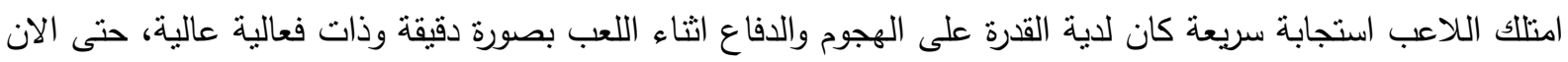

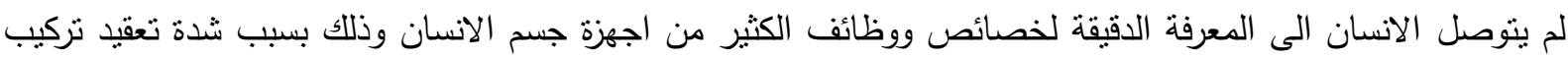
هذه الاجهزة واختلاف وتعدد وتداخل الكثير من الوظائف وهذا التركيب لأجهزة جسم الانسان ارادة الله تعالى ان يكون

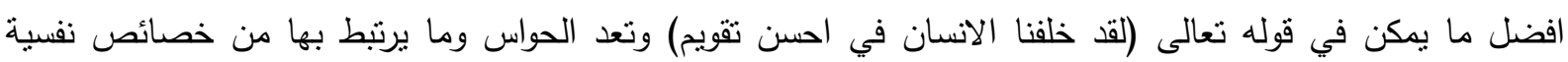
ووظائف حسية من ادق واهم الاجهزة والوظائف التي تؤدي دورها في حياة الانسان وبالرغم من ان استيعاب المعرفة يتوقف فئف فئف

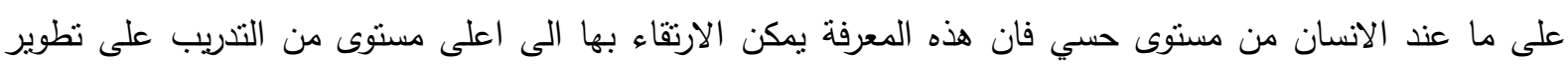

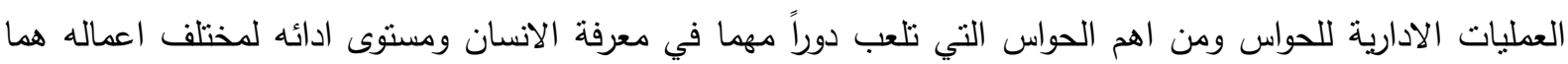

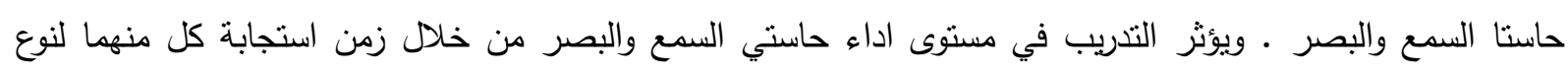

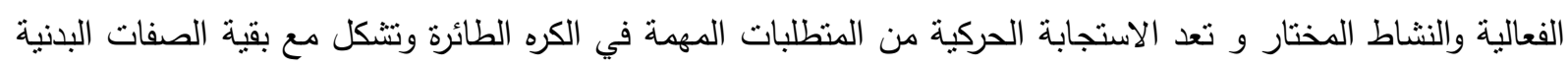

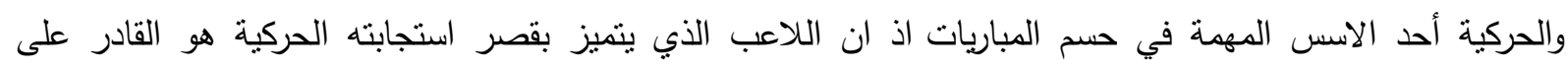

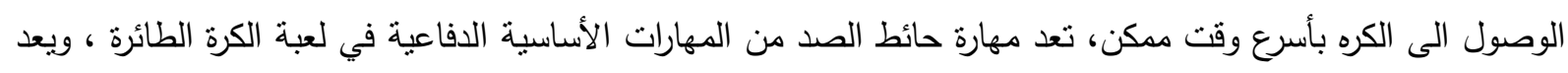

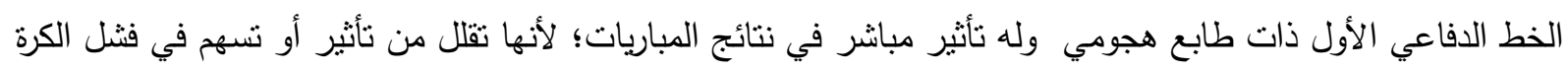
المضروبة الساحقة من المنافس، وهي من المهارة الصعبة من حيث احتباجاتها ومنطلباتها بسبب تميز لعبة كرة الطائرة

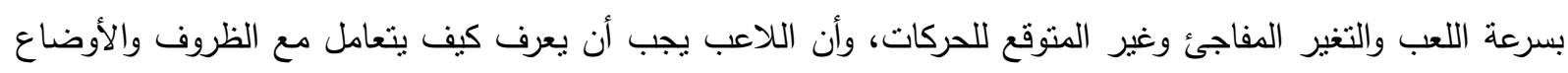

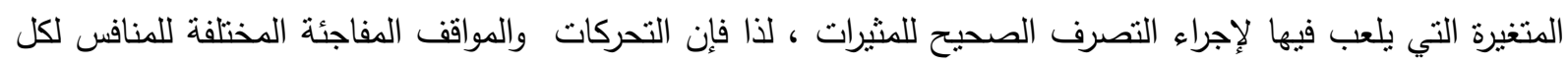

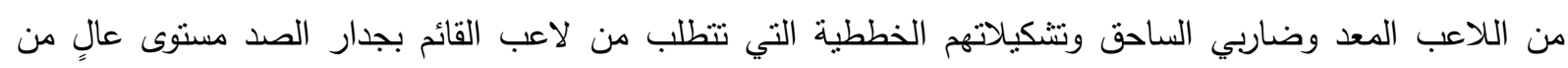

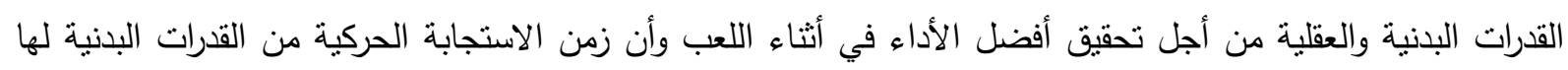

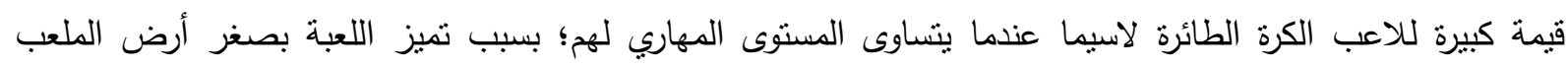

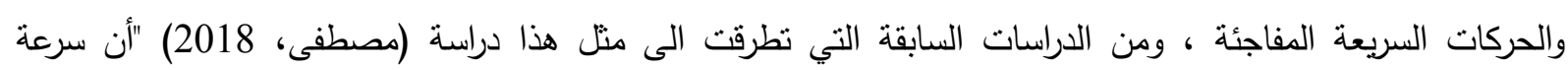

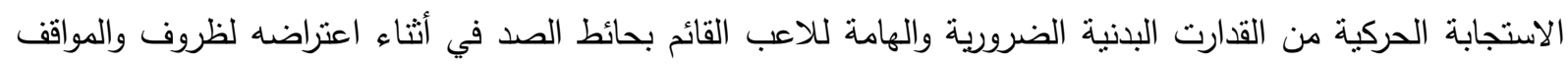

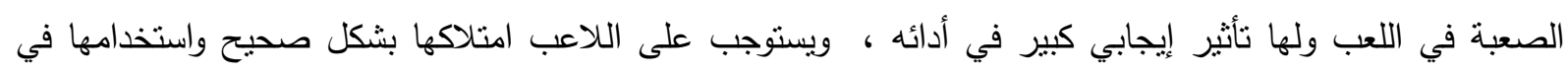

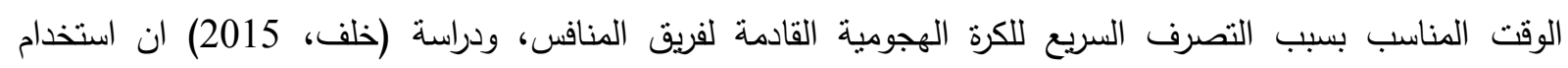
المثيرات الصوتية والمرئية ساعد على نطوير بعض اشكال القدرة العضلية وسرعة الاستجابة الحركية لدقة مهارتي حائط

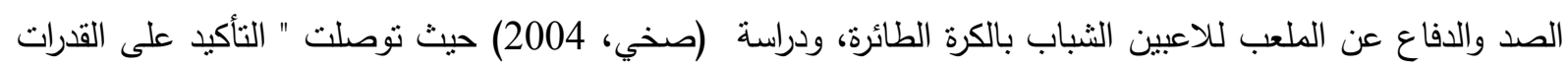
التي لها تأثنير مباشر في دقة الاداء المهاري للاعب الحر خلال الوحدات التدريبية وهي التوقع الحركي وسرعة الاستجابة

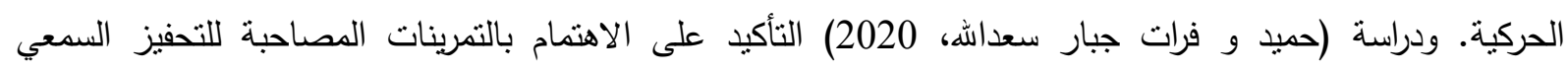

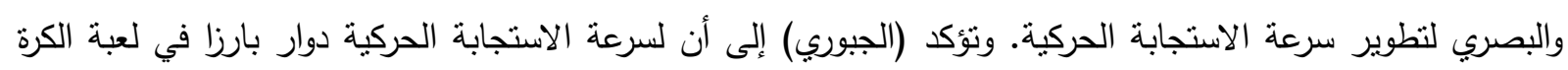

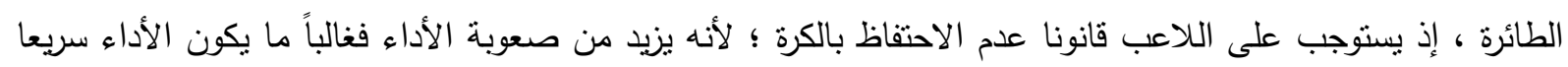

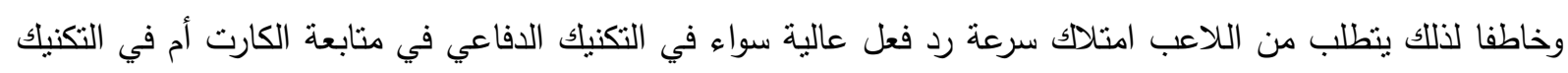

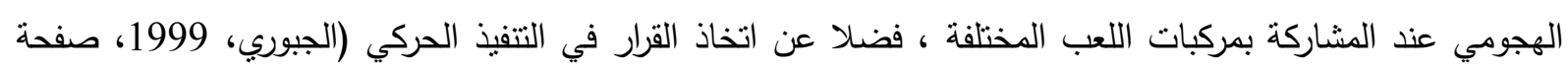
30) ومن هنا تكمن أهمية البحث في التعرف زمن الاستجابة الحركية للمثيرات السمعية والبصرية كمنطلبات أساسية وضرورية للاعبي الكرة الطائرة، وينتج عنهما رد فعل جيد واستجابة حركية صحيحة وسريعة في أثناء أداء مهارة حائط

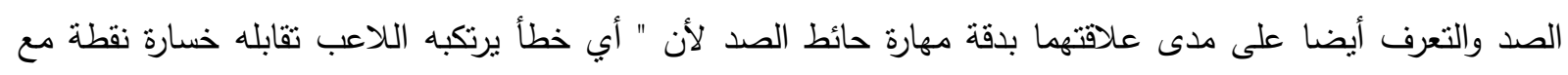


تبديل الإرسال ، لذلك يتطلب من اللاعب طول فنرة المباراة الانتباه والتركيز المستمر لكي يدرك المواقف السريعة والمفاجئة التي تواجهه من أجل الاستجابة الصحيحة لجميع المواقف" (كوليان، 2000، صفحة 11) يعد تطوير القدرات العقلية والبدنية ومنها الاستجابة الحركية من أهم الأسس التي يرتكز عليها نجاح الفعل الحركي، لذلك نرى أن اللاعب يحتاج إلى الفهح والإدرالك لحالات اللعب المختلفة، لتمكن من تكوين استجابة صحيحة وبالوقت المناسب، وتمثل سرعة الاستجابة الحركية مكانة متميزة في تتفذ أداء المهارت الدفاعية بالكرة الطائرة" (محمد و محمد، 1985، صفحة 198) .

\section{الأدوات والإجراءات:}

اعتمد الباحثان على المنهج الوصفي بأسلوب العلاقات الارتباطية، تكون مجتمع البحث من لاعبي اندية دوري

النخبة العراقي للموسم (2019-2020) والبالغ عددهم (7) اندية بواقع (80) لاعب اما عينة البحث تكونت من لاعبي نادي الجيش والثرطة الرياضي البالغ عددهم (24) لاعب إذ تم استبعاد اللاعب اللييرو (كونه لا يسمح له بأداء مهارة حائط الصد لأنه لاعب دفاعي) وقسمت العينة الى (10) لاعبين بنسبة(12.5) من نادي الثرطة للعينة الاستطلاعية التي أقيمت على قاعة الثتب المغلقة و (12) لاعب بنسبة(15\%) من المجتمع الكلي يمثلون نادي الجيش للتجربة الرئيسية التي أقيمت على قاعه نادي الأرمني لكرة الطائرة والجدول (1) يبين تفاصيل توزيع العينة. الجدول (1) يبين تفاصيل توزيع العينة

\begin{tabular}{|c|c|c|c|c|}
\hline النسبة المئوية\% & العينة الرئيسة & العينة الاستطلاعية & عدد اللاعبين & الاندية \\
\hline \multirow[t]{5}{*}{$\% 12.5$} & & 10 & 14 & الشرطة \\
\hline & & & 14 & البيشمركة \\
\hline & & & 12 & البحري \\
\hline & & & 12 & اربيل \\
\hline & & & 12 & الدغارة \\
\hline \multirow[t]{2}{*}{$\% 15$} & 12 & & 14 & الجيش \\
\hline & & & 14 & غاز الجنوب \\
\hline المجموع & 12 & 10 & 80 & 7 \\
\hline
\end{tabular}

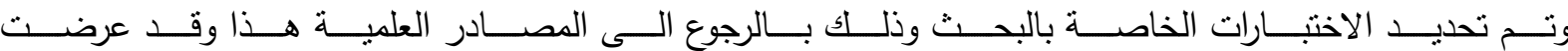

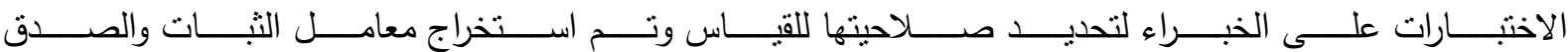
والموضوعية.

أولاً: اختبار زمن الاستجابة الحركية للمنير (السمعي) (الطائي، 2015، صفحة 61): أسم الاختبار : اختبار صقر. الغرض من الاختبار : قياس زمن الاستجابة الحركية بمثير سمعي.

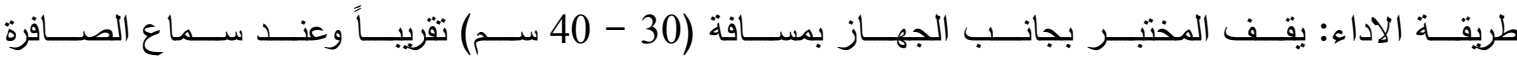

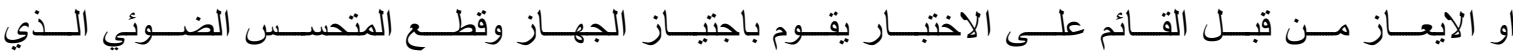

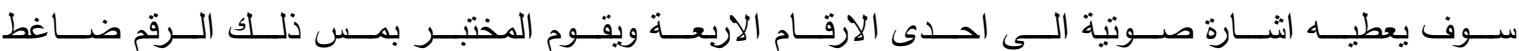

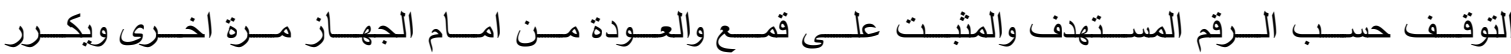

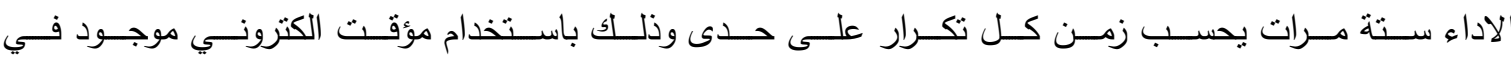

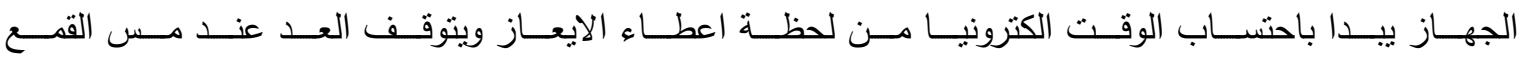




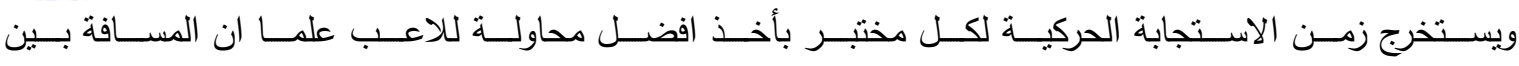

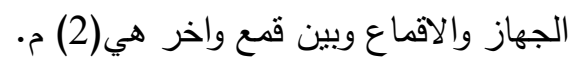

$$
\text { شروط الاداء: }
$$

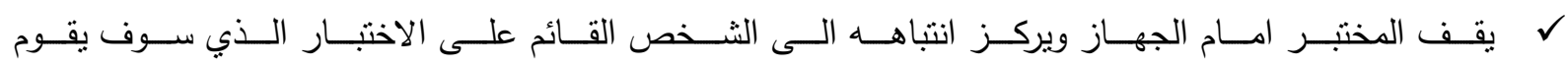
بإعطائه ايعاز البداية.

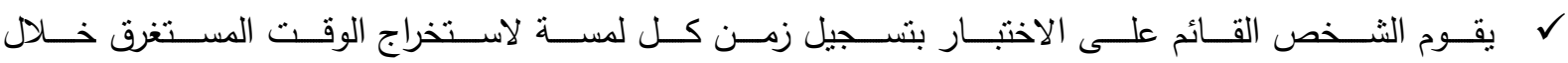
6 ل تعاد المحاولة للمختبر فقط في حالة الاصابة او السقوط بعد مدة راحة كافية. • طريقة التسجيل: يحسب زمن اللمسات ال (6) كل لمسة على حدى ويأخذ زمن أفضل محاولة.

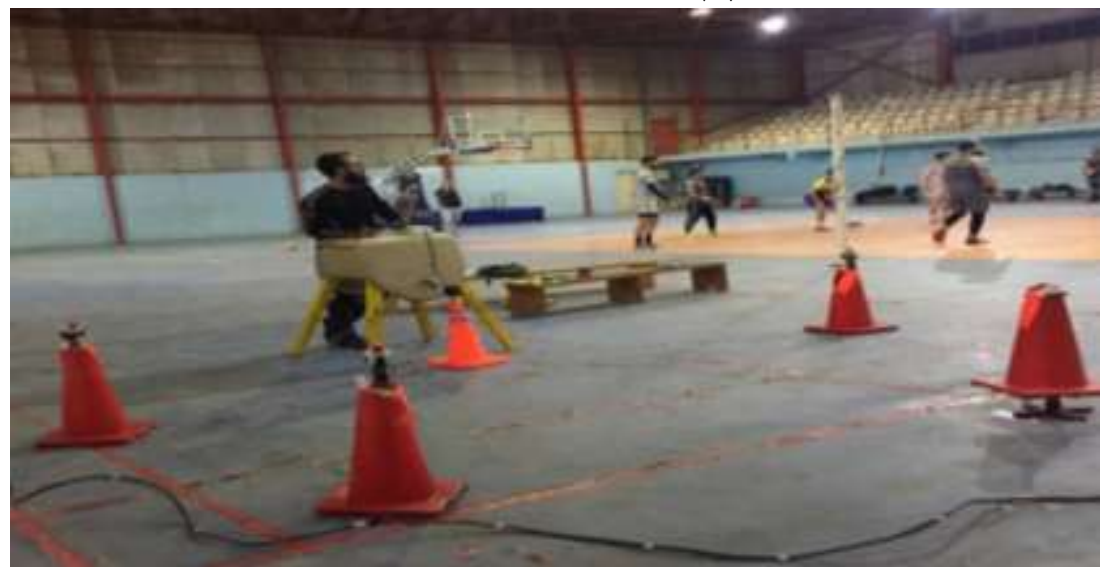

الثكل (1) يوضح اختبار زمن الاستجابة الحركية للمثير (السمعي)

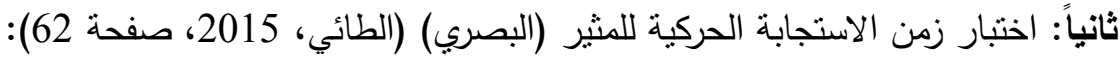

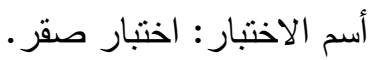

الغرض من الاختبار : قياس زمن الاستجابة الحركية بمثير بصري.

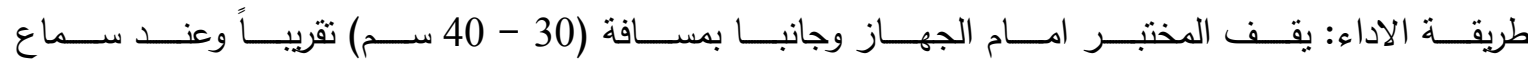

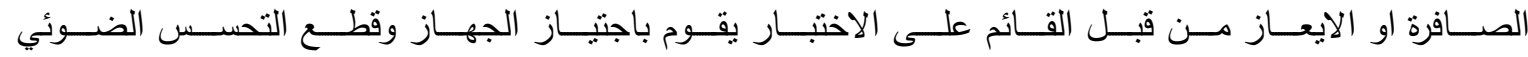

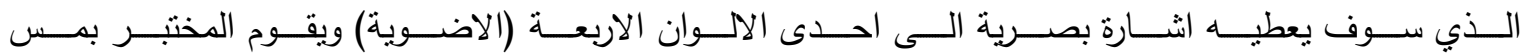

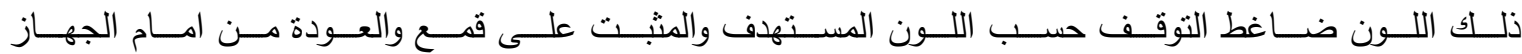

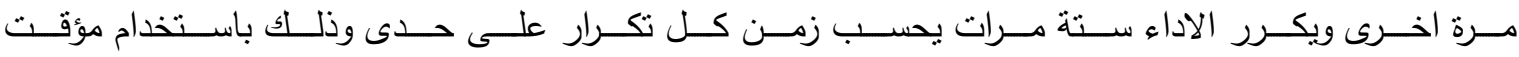

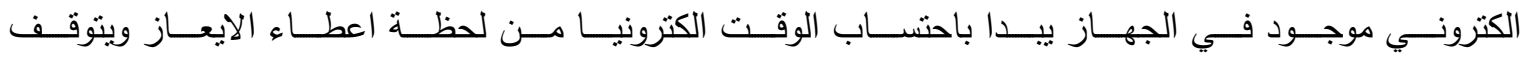

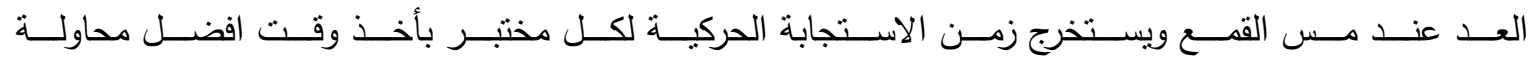
من المحاولات الست علما ان المسافة بين الجهاز والاقماع وبين قمع واخر هي (2) م.

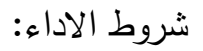

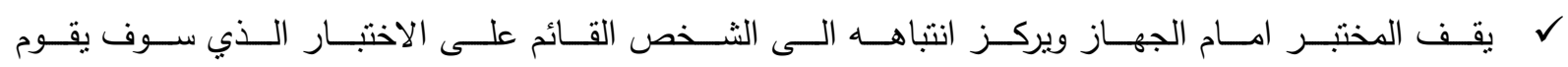
بإعطائه ايعاز البداية.

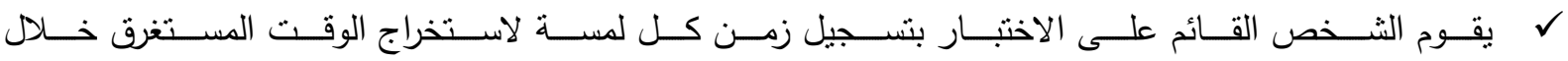
6

ل ت لعاد المحاولة للمختبر فقط في حالة الاصابة او السقوط بعد مدة راحة كافية. • طريقة النسجيل: يحسب زمن اللمسات ال (6) كل لمسة على حدي ويأخذ زمن أفضل محاولة. 


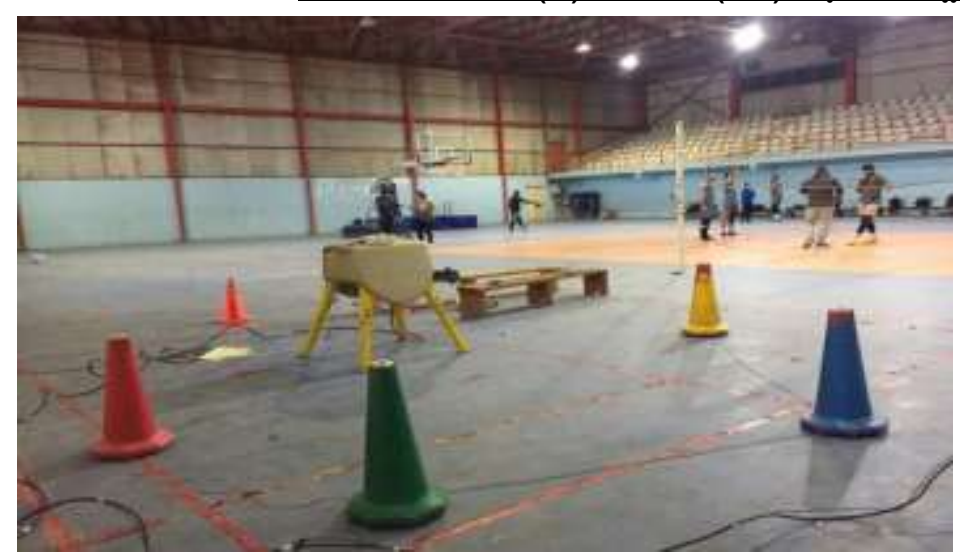

$$
\text { الثكل (2) يوضح اختبار زمن الاستجابة الحركية للمثير (البصري) }
$$

ثالثاً: اختبار دقة أداء مهارة حائط الصد الفردي من مركز (4) و (2) (العزاوي، 2004، صفحة 100): • • الغرض من الاختبار : قياس دقة مهارة حائط الصد الفردي.

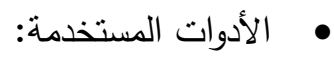
ل

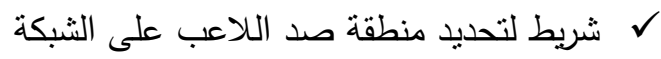

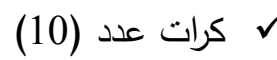

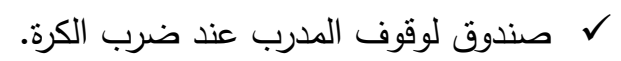

مواصفات الأداء: يقف الدرب على الصندوق ويستعد اللاعب التلقي الايعاز من المدرب بضرب الكرة يقوم خلالها

اللاعب بأداء مهارة الصد بتكنيك كامل ومؤديا المحاولات الثلاثة من منطقة رقم (4) وتتبعها منطقة رقم (2).

(4) نقاط للمحاولة داخل منطقة (أ).

(3) نقاط للمحاولة داخل منطقة (ب).

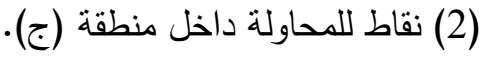

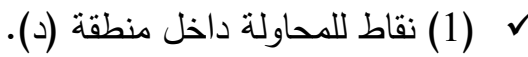

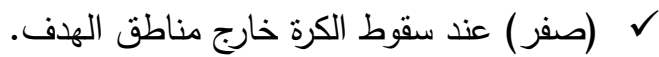

ل وعند سقوط الكرة على الخط بين منطقتين تحسب درجة المنطقة الأعلى، وتلغي المحاولة إذا ارتكب المختبر .

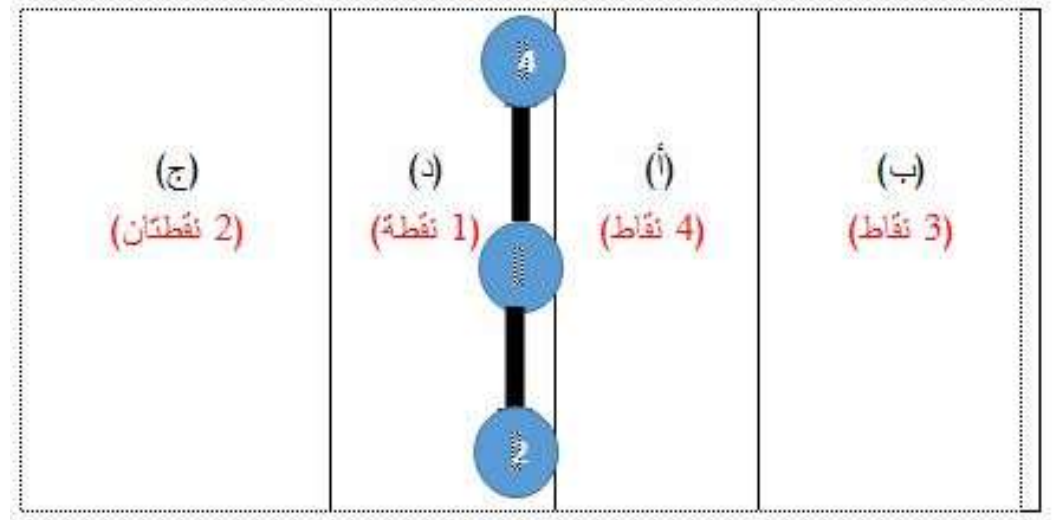

الثكل (3) يوضح اختبار دقة أداء مهارة حائط الصد الفردي من مركز (4) و (2)

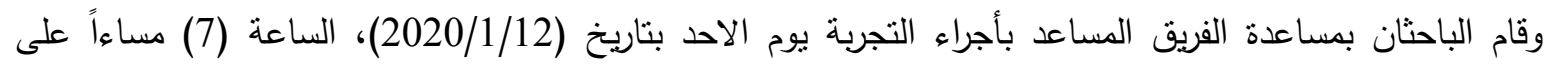
القاعة الثعب المغلقة للألعاب الرياضية على عينة الاسنطلاع والمكونة من (10) لاعبين من نادي الثرطة وهم خارج 


\section{مجلة التربية الرياضية - المجلد (32) - العدد (4) - سنة 2020.}

عينة البحث ،وكان تسلسل اجراء الاختبارات على وفق التسلسل الاتي (زمن الاستجابة الحركية للمثير السمعي، زمن

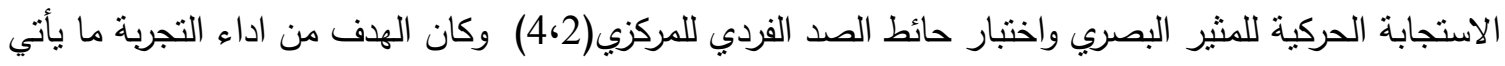
1. التحقق من مدى سلامة الاختبارات وملاءمتها أفراد العينة. 2. معرفة الوقت اللازم لتتفيذ الاختبارات لمراعاة ذلك في الاختبار الأصلي ولئي 3. التعرف على كفاءه الفريق المساعد 4. التعرف على المشاكل المحتمل وقوعها اثثاء تتفيذ الاختبارات الأسس العلمية للاختبارات

صدق الاختبار : لغرض استخراج صدق الاختبارات قام الباحثان باستخدام الصدق الذاتي

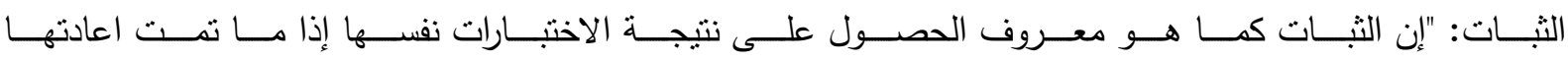

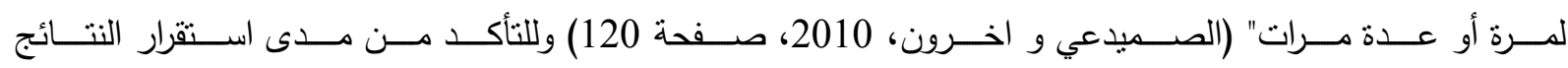

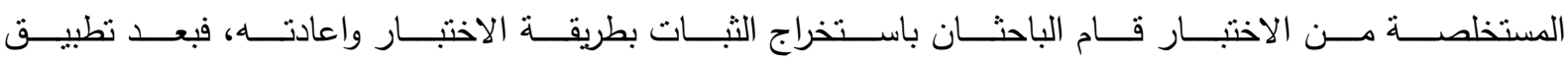

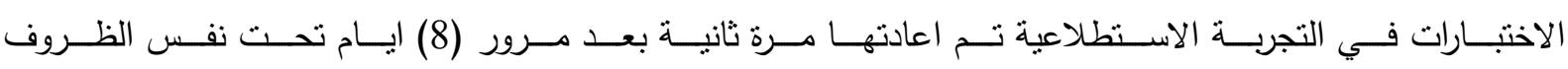

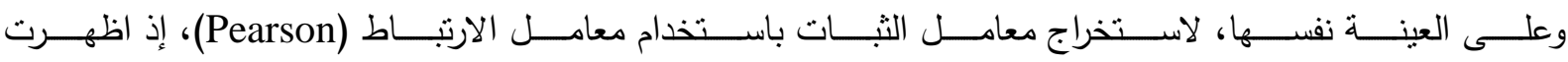

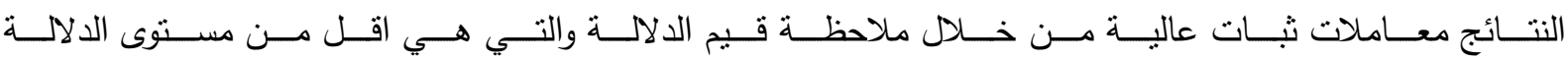

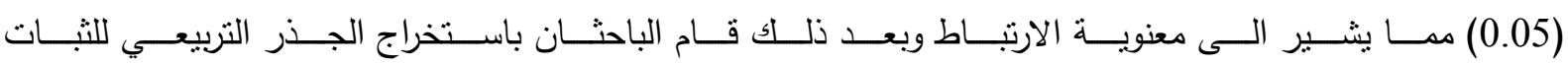

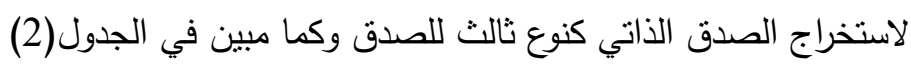
الجدول (2) يبين معامل الثبات والصدق وقيم الدلالة للاختبارات لعينة البحث

\begin{tabular}{|c|c|c|c|c|}
\hline الصدق الذاتي & 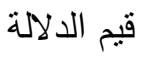 & 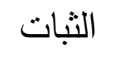 & وحدة القياس & الاختبار \\
\hline 0.795 & 0.000 & 0.633 & 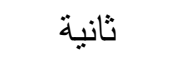 & زمن الاستجابة للمثير (سمعي) \\
\hline 0.912 & 0.000 & 0.833 & ثانية & زمن الاستجابة للمثير (بصري) \\
\hline 0.742 & 0.000 & 0791. & درجة & اختبار دقة حائط الصد من مركز (2) \\
\hline 0.913 & 0.000 & 0.834 & درجة & اختبار دقة حائط الصد من مركز (4) \\
\hline
\end{tabular}

عند درجة حرية ن-2=8 ومستوى دلالة > 0.05

الموضوعية: وتعني "عدم اختلاف المقدين في الحكم على شيء ما أو على موضوع معين" (باهي، 1999، صفحة

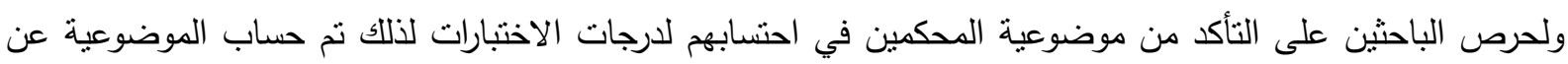

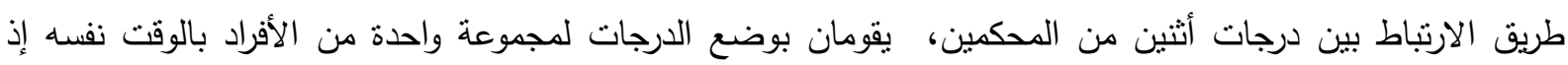

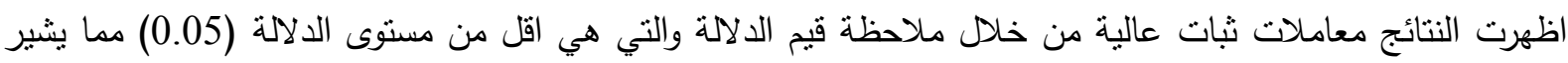

الى معنوية الارتباط وكما مبين في الجدول (3). الجدول (3) يبين معامل الموضوعية للاختبارات والقيم

\begin{tabular}{|c|c|c|c|c|}
\hline قيم الدلالة & الموضوعية & وحدة القياس & الاختبار & $ت$ \\
\hline 0.000 & 0.653 & ثانية & زمن الاستجابة للمثير (سمعي) & 1 \\
\hline 0.014 & 0.784 & ثانية & زمن الاستجابة للمثير (البصري) & 2 \\
\hline 0.000 & 0.653 & درجة & اختبار دقة حائط الصد من مركز (2) & 3 \\
\hline 0.017 & 0.789 & درجة & اختبار دقة حائط الصد من مركز (4) & 4 \\
\hline
\end{tabular}

"عند درجة حرية ن-2=8 0.05 ومستوى دلالة 
قام الباحثان بإجراء التجربة الرئيسية والاختبارات على عينة البحث يوم الثلاثاء الموافق (2020/1/21)، الساعة السادسة

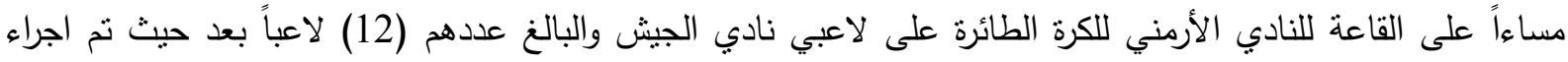
اختباري زمن الاستجابة الحركية للمثير السمعي والبصري وبعدها نم اجراء اختبار حائط الصد الفردي من مركزي (2، (4) وبلغ الزمن الكلي للاختبارات هو (2) ساعة.

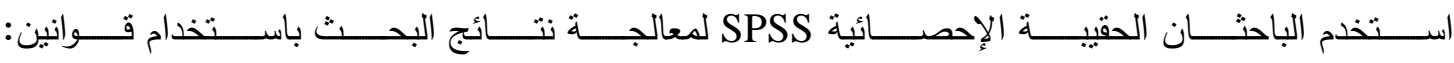

الوسط الحسابي والانحراف المعياري ومعامل الالتواء والنسب المئوية ومعامل الارتباط بيرسون

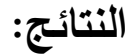

الجدول (4) يبين قيم الأوساط الحسابية والانحرافات المعيارية ومعامل الالتواء ودقة حائط الصد من مركزي (2،4)

\begin{tabular}{|c|c|c|c|c|}
\hline معامل الالتواء & الانحراف & $\begin{array}{l}\text { الحسابي } \\
\text { الوسط }\end{array}$ & وحدة & 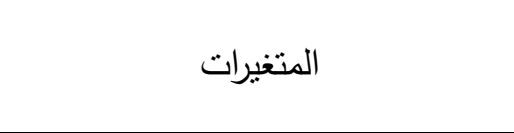 \\
\hline $0.313-$ & 0.11881 & 0.8167 & 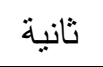 & زمن الاستجابة الحركية للمثير السمعي \\
\hline $0.517-$ & 0.12788 & 0.8558 & 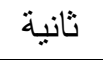 & زمن الاستجابة الحركية للمثير البصري \\
\hline $0.402-$ & 3.60450 & 9.0833 & 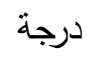 & دقة حائط صد مركز (2) \\
\hline 0.817 & 1.97523 & 9.9167 & 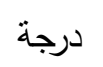 & دقة حائط الصد مركز (4) \\
\hline
\end{tabular}

الجدول (5) يبين قيم الارتباط ونسبأ الخطأ لزمن الاستجابة الحركية للمثير السمعي ودقة حائط الصد لمركزي (2،4)

\begin{tabular}{|c|c|c|c|c|}
\hline النتيجة & مستوى الخطأ & معامل الارتباط & المتغيرات & ت \\
\hline معنوي & 0.000 & $0.707 *$ & دقة حائط الصد مركز (2) & 1 \\
\hline معنوي & 0.000 & $0.778 * *$ & دقة حائط الصد مركز (4) & 2 \\
\hline
\end{tabular}

معنوي عند نسبة الخطأ > (0.05)

الجدول (6) يبين قيم الارتباط ونسبأ الخطأ لزمن الاستجابة الحركية للمثير البصري ودقة حائط الصد لمركزي (2،4)

\begin{tabular}{|c|c|c|c|c|}
\hline النتيجة & نسبة الخطأ & معامل الارتباط & المتغيرات & $ت$ \\
\hline معنوي & 0.000 & $0.802 * *$ & دقة حائط الصد مركز (2) & 1 \\
\hline معنوي & 0.010 & $0.507 *$ & دقة حائط الصد مركز (4) & 2 \\
\hline
\end{tabular}

منوي عند نسبة الخطأ $\geq(0.05)$

المناقشة:

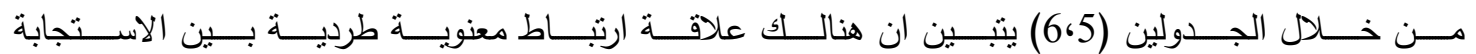

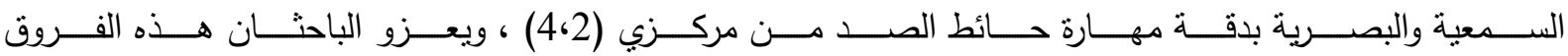

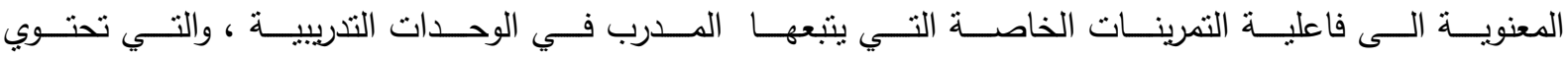

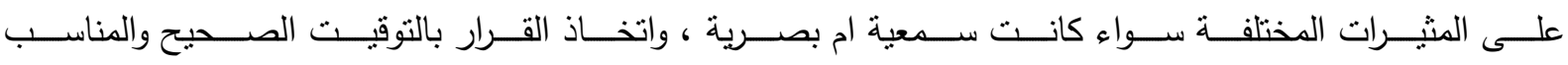

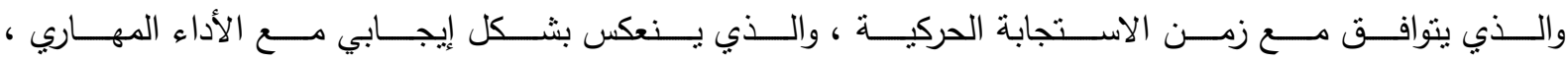

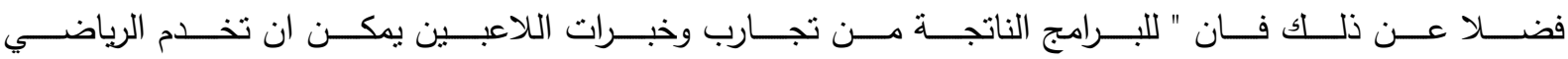




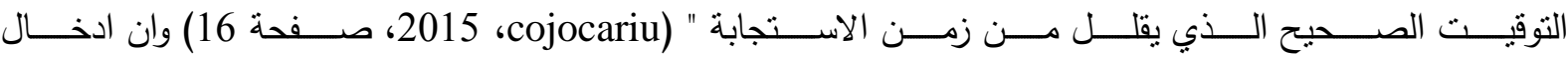

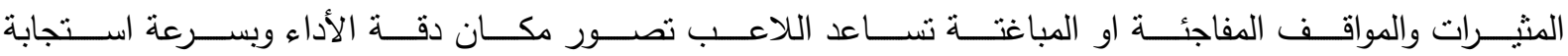

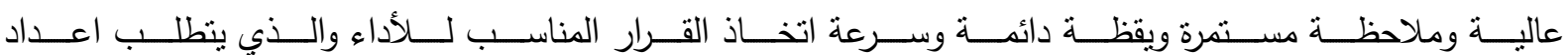

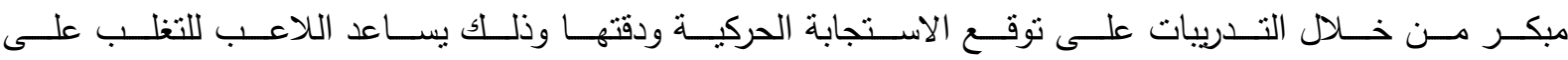

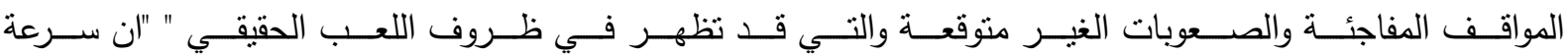

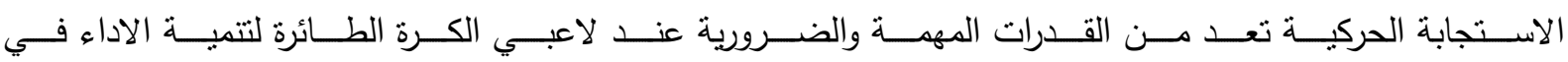

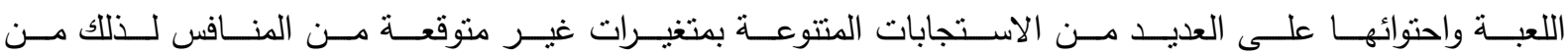

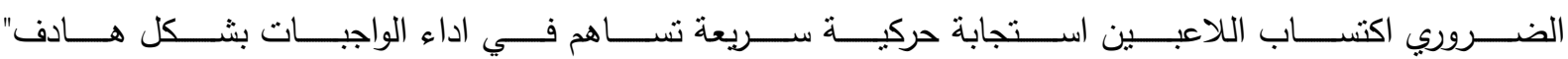

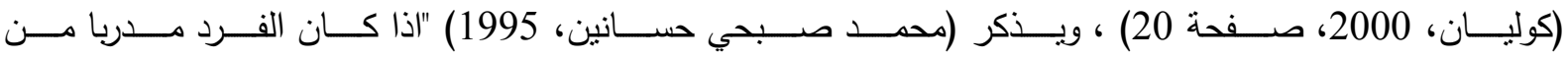

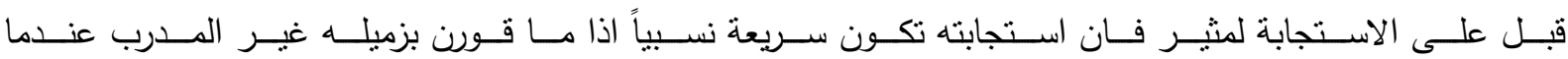

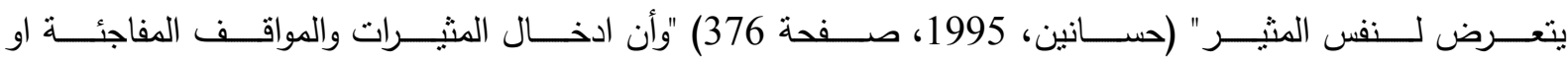

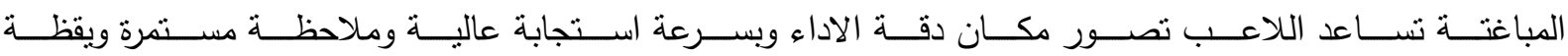

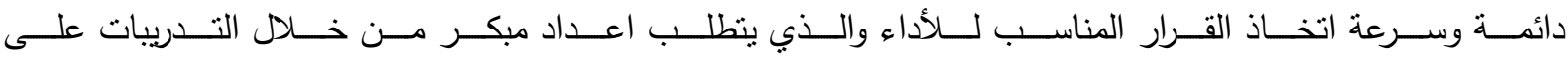

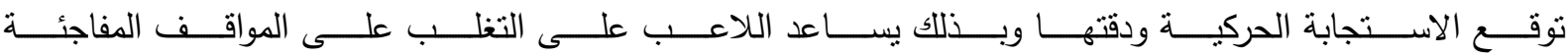

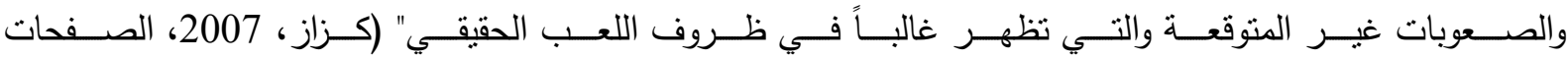

ان زمن الاستجابة الحركية للمثير (السمعي) لهُ تأثير كبير على دقة مهارة حائط الصد بمركزي (4،2) ان زمن الاستجابة الحركية للمثير (البصري) لهُ تأثثر كبير على دقة مهارة حائط الصد بمركزي (4،2) التأكيد على القدرات التي لها تأثثر مباشر في دقة مهارة حائط الصد للاعبين خلال الوحدة التدريبية كزمن الاستجابة الحركية للمثيرات السمعية والبصرية ضرورة التأكيد على بعض التمارين لتطوير زمن الاستجابة الحركية باستعمال الأدوات والتجهيزات المتوفرة. ابتكار العدد من التمارين التي من شأنها تحث على تطوير زمن الاستجابة الحركية لما لها من دور مهم في دقة مهارة الهاب حائط الصد

\section{المصادر}

اوس سعدون سلمان. (2014). أثثر تمرينات خاصة باستخدام بعض الأجهزة والأدوات المساعدة لتطوير سرعة الاستجابة الحركية والدقة لبعض المهارات الفنبة في الكرة الطائرة للاعبين الثباب. رسالة ماجستير غير منشورة، جامعة بغداد، كلية التربية البدنية وعلوم الرياضة. ريتا سهاك كاركين كوليان. (2000). مقارنة بعض القدارت العقلية والبدنية بين لاعبي الكرة الطائرة على وفق تخصصاتهم • رسالة ماجستير ،جامعة بغداد ، كلية التربية الرياضية. شمال صلاح الدين أحمد مصطفى. (2018). ثبات الانتباه وزمن سرعة الإستجابة الحركية وعلاقتهما بأداء ودقة 
شهباء أحمد العزاوي. (2004). اثر التمرينات التوافقية - الأدراكية في تطوير دقة وادراك المهارات الفنية وتقدير الذات المهارية والبدنية للاعبي المنتخب الوطني للناشئين بالكرة الطائرة. بغداد: جامعة بغداد - كلية التربية البدنية وعلوم الرياضية ، للبنات.

صقر غني أرحيم الطائي. (2015). بناء وتقنين اختبارين لقياس زمن الاستجابة الحركية بجهازين بمثير سمعي وبصري على طلاب كلية التربية البدنية وعلوم الرياضية. بغداد: جامعة بغداد كلية التربية البدنية وعلوم الرياضة.

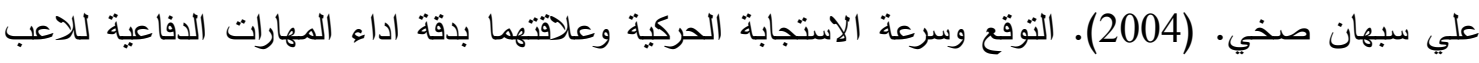
الحر بالكرة الطائرة. جامعة بغداد ،كلية التربية الرياضية.

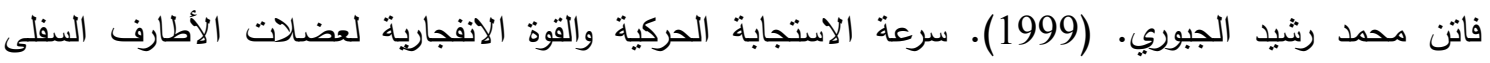

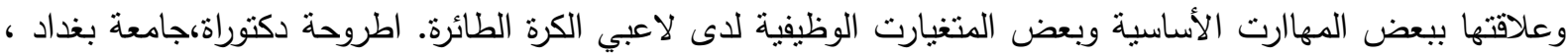
كلية التربية الرياضية. لووي غانم الصميدعي، و اخرون. (2010). الإحصاء والاختبار في المجال الرياضي. اربيل: مديرية دار الكتاب. مازن هادي كزاز. (2007). أثز التنريب العقلي والبدني و المهاري في دقة وسرعة الاستجابة الحركية للاعبي الريشة الطائرة. جامعة بغداد ،كلية التربية الرياضية.

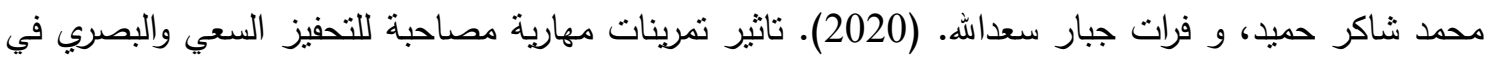
تطوير سرعة الاستجابة الحركية واداء بعض المهارات الاساسية الدفاعية لحراس مرمى كرة القدم للناشئين. مجلة المستتصرية لعلوم الرياضة. محمد صبحي حسانين. (1995). لقياس والتقويم في ألتربية ألبدنية و ألرياضية. القاهرة. محمد قاسم خلف. (2015). تأثير تمرينات خاصة في تطوير بعض اشكال القدرة العضلية وسرعة الاستجابة الحركية لاقة مهارتي حائط الصد والدفاع عن الملعب للاعبين الثباب بالكرة الطائرة ـ جامعة ديالى،كلية التربية البدنية وعلوم الرياضة. مختار محمد، و اسماعيل محمد. (1985). مبادئ علم النفس. الرياض ، السعودية: وزارة المعارف. مصطفى حسين باهي. (1999). المعاملات العلمية والتطبيق (الصدق- الثبات- الموضوعية- المعايير). القاهرة:

$$
\text { مركز الكتاب للنشر. وجية محجوب. (2002). البحث العلمي ومناهجه. بغداد: دار الكتب للطابعة والنشر. }
$$

Adrian cojocariu. .(2015) the effect of the sprcific training upon the values of choicereaction time at the level of the upper limbs in the lawn tennis. Romania: aculty of physical sports university of lasi. 